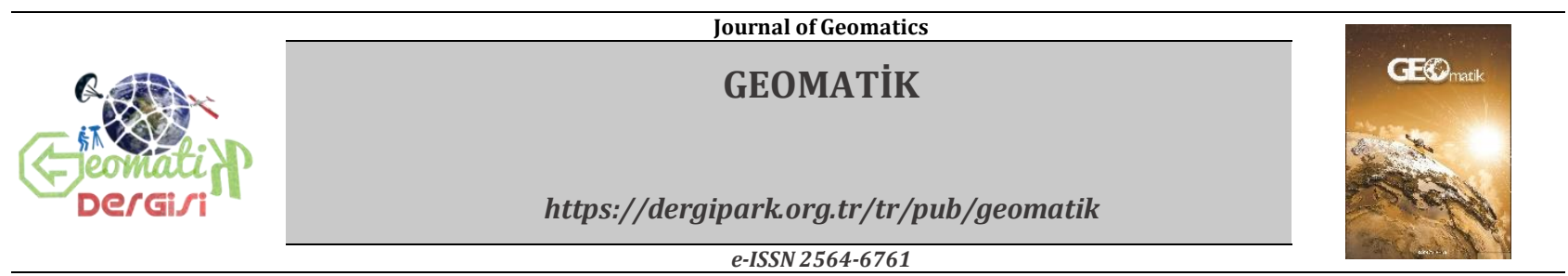

\title{
Deprem kaynaklı olabilecek iyonosferik değişimlerin belirlenmesi üzerine yeni bir yaklaşım geliştirilmesi
}

\author{
Samed İnyurt ${ }^{*}$, Çetin Mekik², Ömer Yıldırım ${ }^{1}$ \\ ${ }_{1}^{1}$ Gaziosmanpaşa Üniversitesi, Mühendislik ve Doğa Bilimleri Fakültesi, Harita Mühendisliği Bölümü, Tokat, Türkiye \\ ${ }^{2}$ Hacettepe Üniversite, Mühendislik Fakültesi, Geomatik Mühendisliği Bölümü, Ankara, Türkiye
}

\begin{abstract}
Anahtar Kelimeler
Öz

GNSS

İyonosfer

Deprem

İyonosfer tabakası yapısı gereği güneş aktivitesi, mevsimsel değişim, gece-gündüz, konum, jeomanyetik aktivite, deprem gibi etmenlere bağlı olarak değişim göstermektedir. Bu tabakada meydana gelen değişim çoğunlukla güneş kaynaklı olsa da sözü edilen diğer etkiler iyonosfer modellemesi için göz önünde bulundurulmalıdır. Günümüzün en büyük doğal afetlerinden biri olan deprem dünya genelinde çok sayıda can ve mal kaybına sebep olmaktadır. Depremle ilgili geçmişten bugüne çok sayıda bilim insanı çalışma yapmıștır. Yapılan çalışmalar sonucunda; deprem öncesi, anı veya sonrasında iyonosfer tabakasında bazı değişimler meydana geldiği, bu sebeple deprem tahmini çalışmalarında iyonosfer tabakasının incelenmesi gerekliliği ortaya koyulmuştur. $\mathrm{Bu}$ çalışma kapsamında deprem kaynaklı iyonosferik anomalilerin belirlenebilmesi için deprem öncesi, anı ve sonrasını kapsayacak şekilde toplam 60 günlük Toplam Elektron Miktarı TEC verisi kullanılmıștır. Alt sınır (LB) ve üst sınır (UB) değerlerinin hassas şekilde belirlenebilmesi için ilk 30 güne ilişkin TEC verilerinden faydalanarak deprem analizi için kullanılacak k değeri belirlenmiştir. Deprem analizi için kullanılacak k değeri elde edildikten sonra deprem kaynaklı TEC değișimlerinin belirlenebilmesi için LB ve UB değerleri her epok için üretilmiştir. Bu sayede iyonosfer tabakasına etki eden mevsimsel değişim ile küçük ve orta seviyedeki jeomanyetik etkilerin deprem kaynaklı iyonosferik değișim analiz sonuçlarına olan etkisinin azaltılması sağlanmıştır. 14 Kasım 2016 (yılın günü 319) tarihinde meydana gelen Yeni Zelanda depreminin merkez koordinatları -42,75 N, 173,07 E olan depremin büyüklüğü Mw 7,8 olarak belirlenmiştir. Yapılan analiz sonucunda 315 ve 317. günlerde pozitif anomaliler görülmüş ve anomali miktarları verilmiştir. Söz konusu anomalilerin depremle ilgili olup olmadığının anlaşılabilmesi için anomali görülen günlerde uzay iklim koşulları detaylı olarak irdelenmiştir.
\end{abstract}

\section{Developing a new approach for determination of possible ionospheric changes caused by earthquake}

\author{
Keywords \\ GNSS \\ Ionosphere \\ Earthquake
}

\begin{abstract}
Ionosphere shows change depending on solar activity, seasonal variation, day-night, geomagnetic activity, earthquake. Even though the change in this layer is mostly caused by the sun, the other effects mentioned should be taken into consideration for ionosphere modeling. One of the natural disasters of modern-day world, the earthquake causes a large number of lives and property loss throughout the world. Many scientists have been involved in studies of earthquake from the past to the present. As a result of the studies; some changes in the ionosphere layer occurred before, during and after the earthquake, and thus ionosphere layer should be monitored effectively. In order to determine anomalies induced by the earthquake within the scope of this study, a total of 60 days of TEC data was used. In order to determine the boundaries of lower bound (LB) and upper bound (UB), the kvalue to be used for earthquake analysis was determined by using TEC data for the first 30 days. After obtaining the $\mathrm{k}$ value to be used for the earthquake analysis, LB and UB values have been produced for each epoch in order to determine the earthquake-induced ionosphere anomaly. In this way, the effect of seasonal change on the ionosphere layer and the effect of small and medium geomagnetic effects on earthquake-induced ionospheric change analysis results will be reduced. As a result of the analysis, positive anomalies were detected 4 days and 2 days before the earthquake respectively. In order to understand whether these anomalies are related to earthquakes or not, spaceweather conditions were examined in the days of anomalies detail.
\end{abstract}

*(samed_inyurt@hotmail.com) ORCID ID 0000 - 0001 - 9339 - 7569 (cmekik@hotmail.com) ORCID ID 0000 - 0002 - 5911 - 4032 (omer.yildirim2002@gmail.com) ORCID ID 0000 - 0002 - 3537 - 6732
İNYURT, S , MEKİK, C , YILDIRIM, Ö . (2020). Deprem Kaynaklı Olabilecek İyonosferik Değișimlerin Belirlenmesi üzerine yeni bir yaklașım gelistirilmesi. Geomatik, 5 (2) , 127 133. DOI: $10.29128 /$ geomatik.592477 Retrieved from https://dergipark.org.tr/tr/pub/geomatik/issue/52495/592477 


\section{GİRIŞ}

Deprem, sahip olduğu yıkıcı etki sebebiyle çok sayıda can ve mal kaybına sebep olmaktadır. Bu sebeple deprem tahmini konusunda farklı disiplinlerden çok sayıda bilim insanı deprem tahmini konusunda çalışma yapmaktadır. Son yıllarda iyonosfer-deprem ilişkisi üzerine pek çok çalışma yapılmıştır. $\mathrm{Bu}$ çalışmalar sonucunda deprem öncesi, anı veya sonrasında iyonosfer tabakasında bazı değişimler meydana geldiği, bu sebeple deprem tahmini çalışmalarında iyonosfer tabakasının incelenmesi gerekliliği ortaya koyulmuştur. İyonosfer tabakasının en önemli fonksiyonu olan TEC, iyonosferde serbest halde bulunan toplam elektron miktarını ifade eder. İyonosfer-deprem ilişkisine yönelik çalışmalarla ort dünya genelinde büyüklükleri farklılık gösteren depremler incelemiş ve TEC miktarı değişimi ile ilişkisi ortaya koyulmuştur. Plotkin (2003) çalışmasında 13 Şubat 2001 tarihinde El Salvador'da meydana gelen Mw 6,6 büyüklüğündeki depremi incelemiş ve depremden 2 gün önce GPS alıcısından elde edilen TEC değerlerinde düşüş yaşandığı kaydedilmiştir. Çalışmada söz konusu değişimin jeomanyetik aktivite veya solar rüzgar kaynaklı olabileceği belirtilmiştir.

Pulinets vd. (2003) yapmış olduğu çalışmada Mw>5 olan depremlerinde \%73'ünde Mw>6 olan depremlerin \%100'ünde depremden önceki 5 gün içerisinde iyonosferik anomaliler meydana geldiğini saptamıştır. Liu vd. (2004) yapmış olduğu çalışmada Tayvan'da 1999-2002 yılları arasında meydana gelen 20 adet depremi hareketli medyan yöntemi ile irdelemiştir. Çalışmanın sonucunda Mw $\geq 6$ depremleri için söz konusu metodun depremden önceki 5 gün içerisinde deprem kaynaklı iyonosfer değişimlerini saptamada \%80 oranında başarı sağladığını belirtmiştir. Fujiwara vd. (2004) yapmış olduğu çalışmada $\mathrm{Mw} \geq 4,8$ olan depremlerde deprem öncesi iyonosferik anomalileri hareketli medyan yöntemi ile irdelemiştir. Çalışma sonucunda depremden önceki 5 gün içerisinde iyonosferde ciddi değişimler meydana geldiğini saptamıștır. Liu vd. (2006) Tayvan bölgesinde 1994-1999 yılları arasında $\mathrm{Mw} \geq 5$ olan 184 adet depremin, iyonosferin F2 tabakasının yüksekliği ve f0F_2 kritik frekansı değişimleri ile olan ilişkisini irdelemiştir. Yapılan çalışma sonucunda f0F_2 kritik frekansındaki anormal düșüşlerin \%25'lik kısmının depremden önceki 5 gün içerisinde yerel zamanda 12:00-18:00 saatleri arasında gerçekleştiği anlaşılmıştır. Bunun yanında deprem öncesi iyonosferik değişimlerin depremin büyüklüğü ile doğru orantılı olduğu, deprem merkezinden uzaklaştıkça iyonosferik anomalilerin düşüş gösterdiği anlaşılmıştır. Söz konusu durumun deprem kaynaklı enerji salınımı ile ilgili olduğu düşünülmektedir.

Liu vd. (2009) yapmış olduğu çalıșmada GIM haritaları yardımıyla 01.05.1998-30.04.2008 yılları arasında Çin'de gerçekleşen $\mathrm{Mw} \geq 6,0$ olan 35 adet deprem irdelenmiştir. Yapılan çalışma sonucunda
Mw $\geq 6,3$ olan 17 adet depremde, depremden önce 35 gün içerisinde TEC değerlerinde ciddi azalmalar meydana geldiği vurgulanmış, 12.05.2008 tarihinde Çin'in Wenchuan bölgesi yakınlarında meydana gelen $M w=7,9$ büyüklüğündeki depremin iyonosfer tabakasında meydana getirdiği olası değișim hem GIM-TEC değerleriyle hem de FORMOSAT3/COSMIC (F3C) uydularından elde edilen elektron yoğunluğu değerleriyle izlenmiştir. Çalışma sonucunda GIMTEC değerlerinde deprem öncesi azalma görüldüğü, F3C uydularından elde edilen sonuçlar irdelendiğinde N_m F_2, h_m F_2 değerlerinde yaklaşık \%40 düşüş yaşandığı kaydedilmiştir. Saroso vd. (2008) yapmış olduğu çalışmada 1993-2002 yılları arasında büyüklüğü $M w \geq 5,9$ olan Sulawesi depremleri ve 26.12.2004 tarihinde gerçekleşen Sumanda-Andaman depremi irdelenmiștir. Deprem kaynaklı TEC değişimlerinin tespit edilmesi amacıyla deprem öncesi ve sonrası 15 günlük TEC değerleri kullanılarak üst ve alt sinırlar oluşturulmuştur. Çalışma sonucunda depremden 2-7 gün öncesinde TEC değerlerinde ciddi düşüşler yaşandığı görülmüştür. Özellikle Sumanda-Andaman depreminde meydana gelen deprem kaynaklı anomalilerin deprem merkezinden $1.600 \mathrm{~km}$ uzaklıkta tespit edilebildiği belirtilmiştir.

$\mathrm{Bu}$ çalışma, 14 Kasım 2016 tarihinde Yeni Zelanda'da meydana gelen depreme ilişkin deprem öncesi ve sonrası deprem kaynaklı TEC değişimlerinin tespit edilmesini amaçlamaktadır. Söz konusu depremin merkez koordinatları $(-42,75$ N, 173,07 E), depremin derinliği $15 \mathrm{~km}$, büyüklüğü Mw 7,8 olarak belirlenmiştir.

\section{YÖNTEM}

Deprem kaynaklı iyonosferik anomalilerin belirlenmesinde çok sayıda istatistiksel yöntem kullanılmıștır. $\mathrm{Bu}$ yöntemlerden biri Liu vd. (2009) önermiş olduğu çeyrekler arası fark bazlı hareketli medyan istatistik analizidir. Bu yöntemde, ilk olarak hareketli ortanca (M), birinci çeyrek (LQ) ve üçüncü çeyrek(UQ) değerleri elde edilir. Daha sonra kestirilen GPS-TEC değerlerinin ortalama değeri (m) ve standart sapması $(\sigma)$ olan normal dağılımda oldukları varsayımı ile $\mathrm{m}$ ve 1,34 $\sigma$ aralığında kabul aralığı olarak seçilmektedir. Sonuç olarak GPS-TEC değerlerinin deprem öncesi ve sonrası 15 gün için hareketli alt sınır ve üst sınır elde edilmektedir. Kullanılan yöntem bir örnekle anlatılacak olursa, ilk 15 güne ait TEC verileri kullanılarak üretilecek medyan, LQ ve UQ değerleri 16. gündeki TEC değerlerinin analizinde referans veri olarak kullanılacaktır. Yine benzer biçimde 2 ile 16 'ncı gün arasındaki TEC verileri 17. güne ait LB ve $U B$ sınırlarının olușturulmasında kullanılacaktır. Bu durumda ilgili epoktaki TEC değeri \%60-65 güvenilirlik seviyesi ile söz konusu sınır değerlerin arasında olacaktır (Liu vd. 2009). Eğer analiz edilen güne ilişkin TEC değerlerinin $1 / 3$ ve daha fazlası üst sınır değerden fazla veya alt sınır değerden az ise 
bugün anomalinin yaşandığı gün olarak ifade edilmektedir (Liu vd. 2004).

Akhoondzadeh vd. (2010) yapmıș oldukları çalışmada, Liu vd. (2009)'da önermiş olduğu yöntemdeki LB ve UB sınırlarını belirlemede kullanılan $\mathrm{k}$ değerinin sabit olduğunu bu nedenle $\mathrm{k}$ değerinin her deprem için farklı olması gerekliliğini ortaya koymuştur. Diğer yandan, UB ve LB değerlerinin belirlenmesinde yaklașık 55 günlük veri kullanılmasının iyonosfer tabakasında var olan sezonsal değişim etkilerinden arındırılması açısından uygun olacağı düşünülmüştür. Akhoondzadeh vd. (2010) yapmiș oldukları çalışmada LB ve UB sınırlarını aşağıdaki denklemler aracılığıyla belirlemiştir. TEC değerinin elde edilmesinde temel bağıntılar (1), (2) ve (3) denklemleri ile gösterilmiştir.

$$
\mathrm{STEC}=-\frac{\mathrm{f}_{1}^{2} \mathrm{f}_{2}^{2}}{40.3\left(\mathrm{f}_{1}^{2}-\mathrm{f}_{2}^{2}\right)} \mathrm{P}_{4, \mathrm{a}}^{\mathrm{u}}-\mathrm{c}\left(\mathrm{DCB}^{\mathrm{u}}+\mathrm{DCB}_{\mathrm{a}}\right)
$$

$\operatorname{VTEC}=\mathrm{MF}(\mathrm{z})^{*}$ STEC

$$
\mathrm{MF}(\mathrm{z})=\cos \left(\arcsin \left(\frac{\mathrm{R}}{\mathrm{R}+\mathrm{H}} \sin (\alpha \mathrm{z})\right)\right)
$$

Bir numaralı denklemde STEC uydu-alıcı arasındaki eğik toplam elektron miktarını, $f_{1}$ ve $f_{2}$ frekansları, $\mathrm{P}_{4, \mathrm{a}}^{\mathrm{u}}$ yumuşatılmış kod gözlemlerini, c ışık hızını, DCB ${ }^{\mathrm{u}}$ ve DCB $_{\mathrm{a}}$ sirasiyla uydu ve alıcıda meydana donanımsal gecikmeyi ifade eder. Her uydu-alıcı çifti arasındaki STEC değerleri elde edildikten sonra haritalama fonksiyonu yardımıyla, $M F(z)$, her epoğa ilişkin VTEC değerleri (2) denklemi aracılığıyla elde edilir(Başçiftçi et al., 2018).

$$
\mathrm{LB}=\mathrm{M}-\mathrm{k}^{*} \mathrm{IQR}
$$

$\mathrm{UB}=\mathrm{M}+\mathrm{k}^{*} \mathrm{IQR}$

$\mathrm{LB}<\mathrm{X}<\mathrm{UB} \quad-k<\frac{x-M}{I Q R}<k \quad D_{x}=\frac{x-M}{I Q R}$

Burada $\mathrm{x}, \mathrm{t}$ zamanına ait gözlemlenen TEC değerini, LB alt sınır TEC değerini, UB üst sınır TEC değerini, M medyan değerini, IQR çeyrekler arası açıklığı, $D_{x}$ gözlemlenen TEC değerinin farkını ifade etmektedir.

Söz konusu çalıșmada $\mathrm{k}$ değerinin depremin büyüklüğüyle orantılı seçilmesi gerektiğini vurgulanmış ve eğer herhangi bir zamana ait hesaplanan $D_{x}$ değeri seçilen k değerinden büyük ise, bu zamana ait TEC değerinin anomaliye sebep olduğu düşünülmektedir. Fakat burada k değerinin elde edilmesiyle ilgili herhangi bir matematiksel ifade ortaya konulmamıştır. Diğer yandan Liu vd. (2009) çalışmasında $m$ ortalama ve $\sigma$ sapmasına sahip GPS-TEC ölçüleri için beklenen $m$ ve $1,34 \sigma$ kabul aralığının iyonosferin alt ve üst sınırlarının belirlenmesi için yetersiz kaldığı düşünülmektedir. Bilindiği üzere iyonosfer tabakası orta enlem bölgesinde ekvatoral ve kutup bölgelerine göre daha sakin davranış göstermektedir. Dolayısıyla her iki bölge için kestirilen TEC değerleri için üst ve alt sinırlarının oluşturulmasında $\mathrm{m}$ ve $1,34 \sigma$ kullanılması doğru bir tasvir olmayacaktır. Yine benzer şekilde iyonosferi etkileyen jeomanyetik etki, solar aktivite gibi etkenler iyonosfer tabakasında farklı bölgelerde farklı etki göstermektedir. Bu sebeple GPS-TEC değerlerinin alt ve üst sınırlarını oluştururken bölgeye uygun olacak şekilde sınırların belirlenmesi gerekliliği ortaya çıkmaktadır. Ĕger analiz edilen bölgeye ilişkin alt ve üst sınır değerler doğru şekilde oluşturulursa, deprem kaynaklı oluşabilecek iyonosferik anomalilerin belirlenmesi daha kolay olacaktır. Sonuç olarak deprem kaynaklı iyonosferik anomalilerin doğru bir şekilde tespiti için öncelikle sınırları olușturacak k değerinin hassas bir şekilde belirlenmesi gerekmektedir.

$\mathrm{Bu}$ çalışma kapsamında deprem kaynaklı iyonosferik anomalilerin belirlenebilmesi için deprem öncesi, anı ve sonrasını kapsayacak şekilde toplam 60 günlük TEC verisi kullanılmıştır. LB ve UB sınırlarının hassas șekilde belirlenebilmesi için ilk 30 güne ilișkin TEC verilerinden faydalanarak deprem analizi için kullanılacak $\mathrm{k}$ değeri aşağıda açıklandığı şekilde belirlenmiştir. Deprem analizi için kullanılacak $\mathrm{k}$ değeri elde edildikten sonra deprem kaynaklı iyonosfer anomalinin belirlenebilmesi için LB ve UB değerleri her epok için üretilmiştir. $\mathrm{Bu}$ sayede iyonosfer tabakasına etki eden mevsimsel değişim ile küçük ve orta seviyedeki jeomanyetik etkilerin deprem kaynaklı iyonosferik değișim analiz sonuçlarına olan etkisinin azaltılması sağlanmış olacaktır.

Çalışmada Liu et al. (2009) yönteminde UB ve LB değerlerinin belirlenmesi için kullanılan formülde yer alan 1.5 sabit değeri Akhoondzadeh vd. (2010 )yönteminde olduğu gibi k değeri olarak düşünülmüştür. Dolayısıyla LB ve UB için oluşturulacak yeni denklem aşağıdaki şekilde ifade edilmektedir. Yazarların çalışmada belirttiği $D_{x}$ değeri gözlemlenen TEC değerinin sapmasını belirtmektedir. Dolayısıyla her epok için gözlemlenen TEC değeri için (Liu et al. 2009) yönteminde olduğu gibi bir sapma değeri elde edilebilir.

$L B=M-k(M-L Q)$

$\mathrm{UB}=\mathrm{M}+\mathrm{k}(\mathrm{UQ}-\mathrm{M})$

$\mathrm{k}_{\mathrm{i}}=\frac{\mathrm{x}_{\mathrm{i}}-\mathrm{M}_{\mathrm{i}}}{\mathrm{IQR}_{\mathrm{i}}}$

(9) denkleminde ki ilgili epoğa ait sapma değerini, $x_{i}$ gözlemlenen TEC değerini, $M_{i}$ medyan değerini, $I_{Q R}$ kartiller arası farkı ifade etmektedir. Her saate ilişkin k değeri analiz edilen günlerden önceki 30 güne ait TEC verisi kullanılmıştır. (6) denklemi kullanılarak her saat için 30 adet $\mathrm{k}$ değeri elde edilmiş ve bunların maksimum değeri alınmıştır. Daha sonra her saate ilişkin elde edilen $\mathrm{k}$ değerlerinin ortalaması alınarak deprem analizi için 
kullanılacak tek bir $\mathrm{k}$ değeri elde edilmiştir. $\mathrm{Bu}$ sayede iyonosferi etkileyen sezonsal değişim, solar etki, jeomanyetik aktivite gibi etkenlerin analiz sonuçlarına olan etkisinin önüne geçileceği düşünülmektedir. Daha sonra (7) ve (8) denklemleri kullanılarak sirasıyla LB ve UB değerleri elde edilmiştir. Tüm bu işlemler için gerekli verilerin indirilmesi, analiz edilmesi gibi işlemler MATLAB ortamında hazırlanan program ile elde edilmiştir.

Çalışmada ikinci yöntem olarak, deprem kaynaklı anomalilerin tespit edilebilmesi amacıyla deprem öncesi ve sonrasını kapsayan 60 günlük gerçek TEC değerlerinden faydalanılarak model oluşturulmuş, bu model aracilığıyla TEC değerlerinin genel davranışı belirlenmiştir. Model sonucunda üretilen TEC değerleri, gerçek TEC değerlerinden çlkarılmış ve elde edilen farklara ilişkin istatistiksel teste $(m \pm 2 \sigma)$ tabi tutularak anomali tespiti yapılması amaçlanmıştır. Burada m ortalamayı, $\sigma$ standart sapmayı ifade etmektedir. Yapılan çalışma sonucunda analiz için kullanılacak elde edilen modele ilişkin denklem aşağıda sunulmuştur.

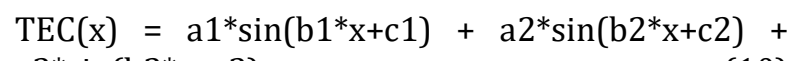

Burada a1, a2, a3 genliği; b1, b2, b3 açısal frekansı; c1, c2, c3 fazı; $x$ ise zamanı temsil etmektedir. Bu çalışmada yukarıda anlatılan iki model kullanılarak her deprem için ayrı ayrı uygulanacak ve ortaya çıkan sonuçlar detaylı olarak irdelenecektir.

\section{UYGULAMA}

İyonosfer-deprem ilişkisinin irdelenebilmesi amacıyla 14 Kasım 2016 tarihinde meydana gelen Yeni Zelanda depremi ele alınmıştır. Merkez koordinatları $(-42,75 \mathrm{~N}, 173,07 \mathrm{E})$ olarak tespit edilen depremin derinliği $15 \mathrm{~km}$, büyüklüğü $\mathrm{Mw}$ 7,8 olarak belirlenmiștir. GIM'e ait TEC verilerinin kullanıldığı çalışmada deprem öncesi ve sonrası 15 güne iliş̧in TEC değişimlerinin irdelenebilmesi için zamansal çözünürlüğü 1 saat olan toplam 60 günlük TEC verisi kullanılmıştır. Yapılan analiz sonucunda çalışmada kullanılacak $\mathrm{k}$ sabiti 2,50 olarak belirlenmiștir.

Şekil 1'de Yeni Zelanda depremine ilişkin deprem öncesi ve sonrası 15 güne ilişkin GPS-TEC değişimleri gösterilmektedir. Şekilde yer alan siyah çizgi alt sınır TEC değerlerini, kırmızıçizgi üst sınır TEC değerlerini, yeşil çizgi medyan TEC değerlerini, kesikli çizgi gözlemlenen TEC değerlerini ifade etmektedir. Çalışmada 315 ve 317. günlerde pozitif anomali tespit edilmiştir.

İlk yönteme göre yapılan analiz sonucunda 315 ve 317. Günlerde pozitif anomaliler tespit edilmiş ve Şekil 1'de gösterilmiștir. Bu günlere ilişkin görülen anomalilerin miktar ve zamanına ilişkin bilgiler Tablo 1'de verilmiştir.

Şekil 2'de deprem öncesi ve sonrası 15 güne ilişkin model aracıllı̆̆ıla elde edilen TEC değerleri ve gerçek TEC değerleri, ve arasındaki fark gösterilmiştir. Elde edile bu fark değerleri üzerinden $(m \pm 2 \sigma)$ istatiksel testine tabi tutularak her epok için alt ve üst sinırlar belirlenmiştir.

Şekil 3 fark değerleri üzerinden yapılan istatistiksel test sonucunda elde edilen anomalili günleri ifade etmektedir. 315 ve 316. günlerde pozitif anomali elde edilmiştir.

İkinci yöntem kullanılarak yapılan analiz sonucunda 315 ve 316 . Günlerde anomali tespit edilmiş ve Şekil 3'te gösterilmiştir. Tespit edilen anomalilerin miktar ve türüne ilişkin bilgiler Tablo 2 'de verilmiştir.

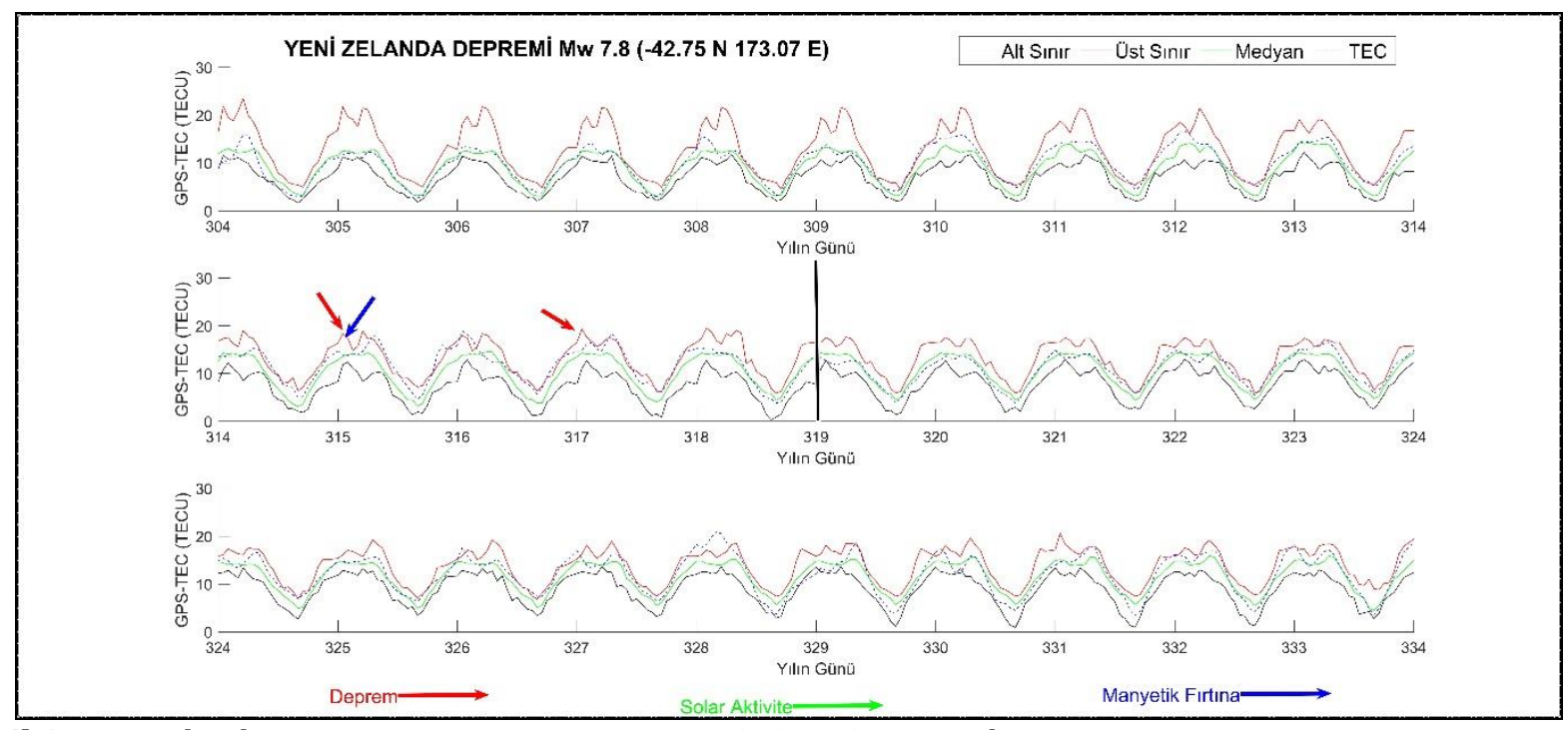

Şekil 1. Yeni Zelanda Depremi öncesi, anı ve sonrası GPS-TEC Değişimleri 

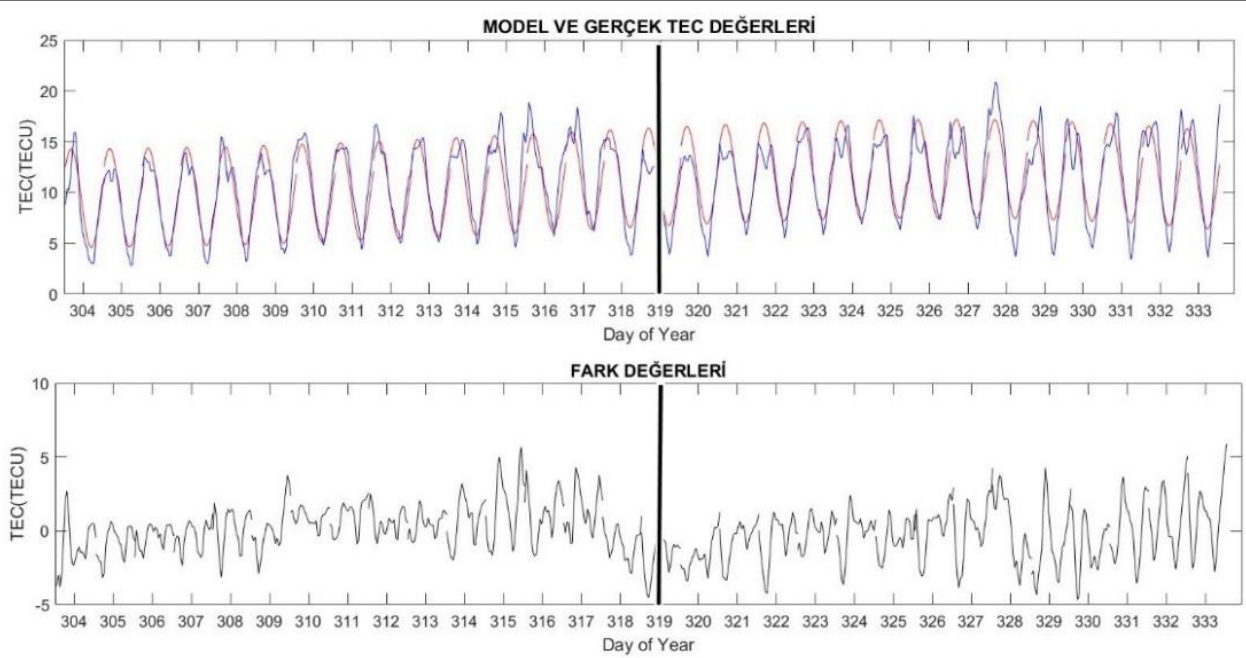

Şekil 2. Yeni Zelanda Depremi öncesi, anı ve sonrası GPS-TEC Değişimleri

Tablo 1. Yeni Zelanda Depremi Anomali Miktarı ve Türü

\begin{tabular}{llll}
\hline Gün & Saat & $\begin{array}{l}\text { Anomali-Değeri } \\
\text { (TECU) }\end{array}$ & $\begin{array}{l}\text { Anomali } \\
\text { Türü }\end{array}$ \\
\hline 315 & 7 & 0,60 & Pozitif \\
315 & 8 & 1,60 & Pozitif \\
315 & 9 & 1,10 & Pozitif \\
315 & 10 & 0,85 & Pozitif \\
315 & 11 & 1,65 & Pozitif \\
315 & 12 & 0,30 & Pozitif \\
315 & 20 & 2,50 & Pozitif \\
315 & 21 & 2,85 & Pozitif \\
317 & 7 & 1,10 & Pozitif \\
317 & 8 & 0,24 & Pozitif \\
317 & 9 & 0,50 & Pozitif \\
317 & 10 & 1,00 & Pozitif \\
317 & 11 & 0,25 & Pozitif \\
317 & 16 & 0,25 & Pozitif \\
317 & 17 & 0,10 & Pozitif \\
317 & 19 & 0,25 & Pozitif \\
317 & 20 & 0,25 & Pozitif \\
317 & 21 & 1,10 & Pozitif \\
\hline
\end{tabular}

Tablo 2. Yeni Zelanda Depremi Anomali Miktarı ve Türü

\begin{tabular}{llll}
\hline Gün & Saat & TEC-Farkı (TECU) & Anomali Türü \\
\hline 315 & 21 & 1,71 & Pozitif \\
315 & 22 & 1,37 & Pozitif \\
316 & 19 & 1,10 & Pozitif \\
316 & 20 & 1,12 & Pozitif \\
\hline
\end{tabular}

Elde edilen anomalilerin deprem ile ilişkisinin olup olmadı̆̆ının anlaşllabilmesi için analiz edilen günlere ilişkin uzay iklim koşulları hakkında bilgi veren $\mathrm{Kp}$, DsT ve F10.7 cm indisleri Şekil 4'de verilmiştir.

Yapılan analiz sonucunda uzay iklim koşullarının 316 ve 317. günlerde oldukça sakin olduğu, 315. günün belirli bölümlerinde jeomanyetik aktivite gerçekleștiği görülmektedir (DsT: $-59 \mathrm{nT}$, Kp*10: 47). Bu nedenle 316 ve 317. günlerde tespit edilen anomalilerin sadece deprem kaynaklı olabileceği, 315. güne ilişkin görülen pozitif anomalilerin manyetik fırtına veya deprem kaynaklı olabileceği düşünülmektedir. Her iki yöntem irdelendiğinde 315 . günde aynı türde (pozitif) anomali tespit edildiği, diğer yandan ilk yöntemde 317 , ikinci yöntemde ise 316 . günde yine aynı türde (pozitif) anomali meydana geldiği görülmektedir. 

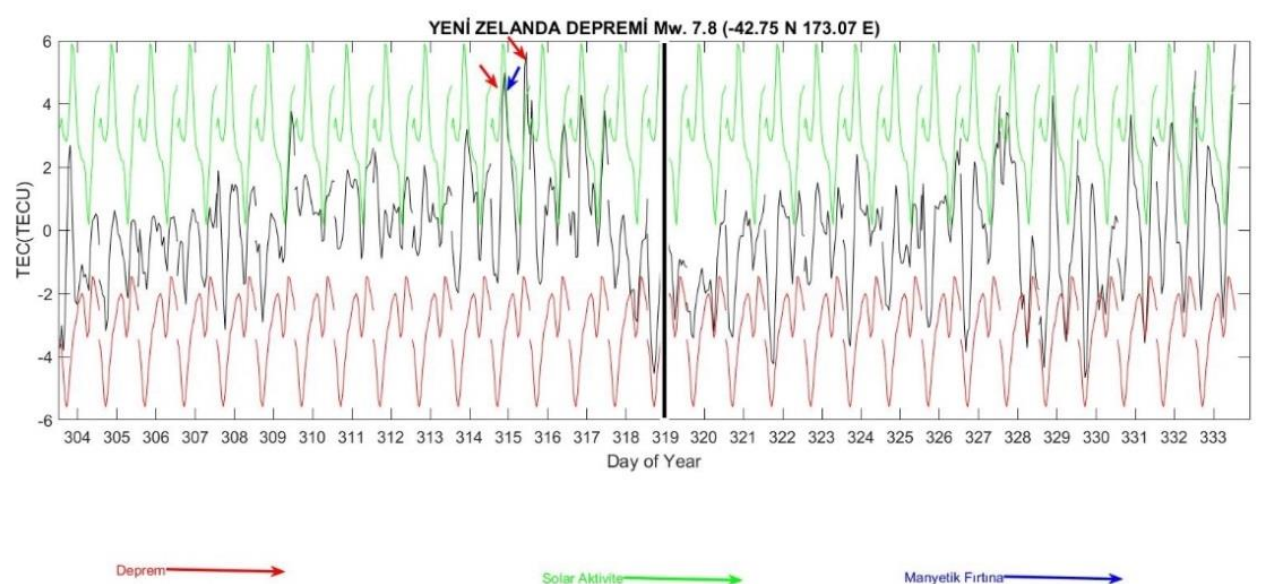

Şekil 3. Fark değerleri üzerinden yapılan analizin gösterimi

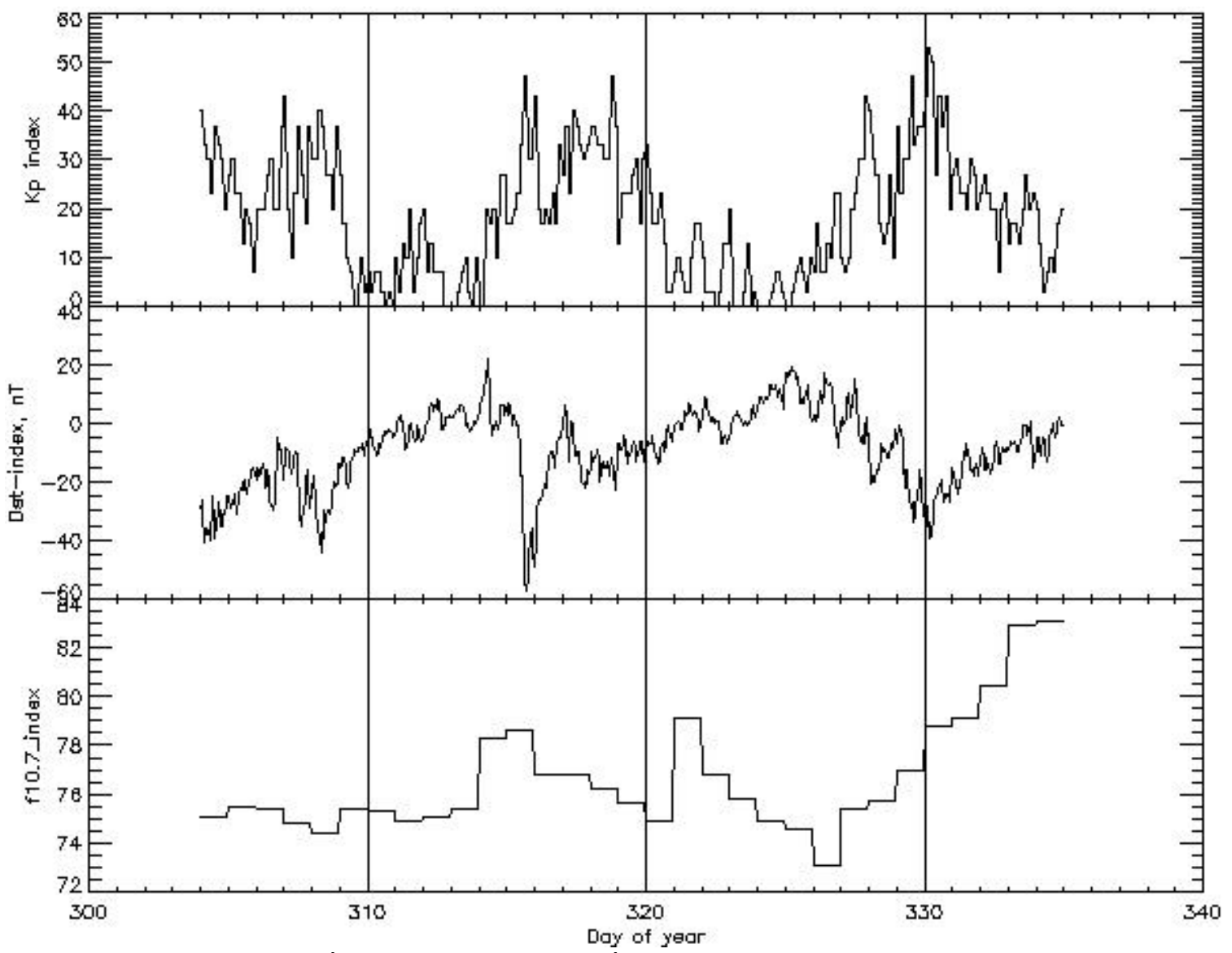

Şekil 4. Analizi Yapılan Günlere İlişkin Kp, Dst ve F10.7 İndislerinin Gösterimi

\section{SONUÇLAR}

Bu çalışmada 14 Kasım 2016 tarihinde meydana gelen Yeni Zelanda depremine ilişkin olası iyonosfer değişimlerin tespit edilebilmesi için iki farklı yöntem uygulanmış ve sonuçları detaylı şekilde irdelenmiștir.

TEC değerlerinin çeyrekler arası fark bazlı hareketli medyan yöntemi ile alt ve üst sınır değerleri deprem öncesi ve sonrası 15 gün için elde edilmiștir. Toplamda 60 günlük TEC verisinin kullanıldığı bu çalışmada deprem bölgesine ilişkin istatistiksel analizde kullanılacak özel bir k değeri belirlenmiștir. $\mathrm{Bu}$ değerin belirlenmesinden sonra uygulanan istatistiksel test sonucunda elde edilen pozitif anomaliler verilmiștir. Söz konusu anomalilerin deprem ile ilişkisinin daha iyi irdelenebilmesi amacıyla iyonosferik koşullar hakkında bilgi veren Kp, DsT ve $\mathrm{F} 10.7 \mathrm{~cm}$ indisleri detaylı bir şekilde incelenmiştir. Çalıșma sonucunda 315 ve 317. günlerde pozitif anomali elde edilmiştir.

İkinci yöntemde ise her bir depreme ilișkin analizde kullanılan toplam 60 günlük TEC verisinin genel davranışının belirlenmesi amacıyla 
matematiksel model oluşturulmuştur. Elde edilen bu model aracılığıyla üretilen TEC değerleri gerçek TEC değerlerinden çıkarılmış ve kalan TEC değerlerinin alt ve üst sınır değerleri her epoktaki TEC değeri için elde edilmiştir. Bu yöntem sonucunda 315 ve 316 . günlerde pozitif anomali elde edilmiştir.

Her iki yöntem kullanılarak yapılan analiz sonuçları, literatür araştırması sonucunda 15 gün öncesi ve sonrası iyonosfer öncüllerinin yakalanabileceği sonucunu desteklemektedir. Diğer yandan her iki yöntemin uygulanması sonucunda 315. günde pozitif anomali tespit edilmiş, buna ek olarak ilk yöntemde 317 . günde ikinci yöntemde ise 316. günde pozitif anomali tespit edilmiştir. Söz konusu bu değişkenliğin istatistiksel yaklaşımların farklı olmasından kaynaklandığı düşünülmektedir.

\section{BİLGILLENDİRME/TEŞEKKÜR}

$\mathrm{Bu}$ çalışma 25.04.2019--27.04.2019 tarihleri arasında Ankara'da düzenlenen Türkiye Harita Bilimsel ve Teknik Kurultayı'nda sözlü bildiri olarak sunulmuştur.

\section{KAYNAKÇA}

Akhoondzadeh M., Parrot M., Saradjian M. R., (2010), Electron and ion density variations before strong earthquakes ( $\mathrm{M}>$ 6.0) using DEMETER and GPS data. Natural Hazards and Earth System Sciences, 10(1): 7-18.

Başçiftçi, F., Inal, C., Yildirim, O., \& Bulbul, S. (2018). COMPARISON OF REGIONAL AND GLOBAL TEC VALUES: TURKEY MODEL. International Journal of Engineering and Geosciences, 3(2), 61-72.

Fujiwara H., Kamogawa M., Ikeda M., Liu J. Y., Sakata H., Chen Y. I., Ohtsuki Y. H., (2004), Atmospheric anomalies observed during earthquake occurrences. Geophysical Research Letters, 31(17): 1-5.

Liu J. Y., Chuo Y. J., Shan S. J., Tsai Y. B., Chen Y. I., Pulinets S. A., Yu S. B., (2004), Pre-earthquake ionospheric anomalies registered by continuous GPS TEC measurements. In Annales Geophysicae, 22: 1585-1593.

Liu J. Y., Chen Y. I., Chuo Y. J., Chen C. S., (2006), A statistical investigation of preearthquake ionospheric anomaly. Journal of Geophysical Research: Space Physics, 111 (A5): 1-4.

Liu J. Y., Chen Y. I., Chen C. H., Liu C. Y., Chen C. Y., Nishihashi M., Lin C. H., (2009), Seismoionospheric GPS total electron content anomalies observed before the 12 May 2008 Mw7. 9 Wenchuan earthquake. Journal of Geophysical Research, 114 (A4): 1-15.
Plotkin V. V, (2003), GPS detection of ionospheric perturbation before the 13 February 2001, El Salvador earthquake. Natural Hazards and Earth System Sciences, 3 (3/4): 249-253.

Pulinets S A, Leyva Contreras A, Bisiacchi-Giraldi G and Ciraolo L, (2003), Total electron content variations in the ionosphere before the Colima, Mexico, earthquake of 21 January 2003. Geofísica Internacional, 4: 369-377.

Saroso S., Liu J. Y., Hattori K., Chen C. H., (2008), Ionospheric GPS TEC Anomalies and $\mathrm{M} \geq 5.9$ Earthquakes in Indonesia during 1993-2002. Terrestrial, Atmospheric and Oceanic Sciences, 19: 481-488. 